\title{
THE EFFECT OF MINERAL FORTIFICATION ON TEXTURAL AND OXIDATIVE STABILITY OF REDUCED-FAT SPREADS
}

\author{
C.E.Stathopoulos ${ }^{\mathrm{a}}$, S.Chockchaisawasdee $^{\mathrm{b}}$, J.Doyle $^{\mathrm{c}}$, B.O'Kennedy ${ }^{\mathrm{a}}$, J.Mounsey ${ }^{\mathrm{a}}$ \\ a: Teagasc, Moorepark Food Research Centre, Fermoy, Co.Cork, Ireland \\ b: Loei Rajabhat University, Dept. of Food Technology, Loei 42000, Thailand \\ c: Kerry Bio-Science, Kilnagleary, Carrigaline, Co.Cork, Ireland
}

Address correspondence to Costas Stathopoulos, Teagasc, Moorepark Food Research

Centre, Co.Cork, Ireland. E-mail: costas.stathopoulos@gmail.com

Running head: Mineral fortification of reduced-fat spreads

Abstract

The aim of this research was to investigate the effect of mineral fortification on he textural and oxidative stability of reduced-fat spreads produced using $\kappa$-carrageenan. Model systems were prepared containing varying amounts of zinc, copper and iron. The hardness of the spreads stored at $5^{\circ} \mathrm{C}$ and $25^{\circ} \mathrm{C}$ was assessed over time using a penetrometer $\left(20^{\circ}\right.$ cone $)$, and samples were generally weaker compared to the controls. Samples containing the transition minerals iron and copper were very susceptible to oxidation, becoming rancid rapidly. Low levels of zinc addition (between $2-10 \%$ RDA) led to spreads with acceptable oxidative stability and a textural profile comparable to the controls over the storage period examined.

Keywords: mineral fortification, $\kappa$-carrageenan, reduced-fat spreads 


\section{Introduction}

Butter and margarine, the traditional oil continuous products for spreading, contain $80 \%$ fat. The large fat phase determines the sensory attributes of flavour release, thickness, sweetness, smoothness and 'melt in the mouth' behaviour. It also dictates the physical properties, rheological characteristics, chemical reactions and microbiological stability of traditional products [1].Additionally, such products derive much of their structure from the fat phase, and few other ingredients were used to tailor the properties of these spreads [2]. In the last three decades a number of economic, medical and social factors have all contributed to the decline in butter consumption, amongst which are widespread availability of fridges, trends towards healthier lifestyles and diets, and very high fat consumption, particularly in the Western world [2-5]. Attempts have been made, therefore, to produce spreads of a high dietary value containing half, a quarter or even less of the fat of butter which, however, retain its desired appearance, texture, flavour and sensory characteristics $[1$, 5]. In products containing less than $20 \%$ fat the emulsion phase inverts, and the fat phase is dispersed within the aqueous matrix. Both fat- and water- continuous preparations contain a disproportionate aqueous phase which will flow unless it is structured somehow [6]. Spreads have to combine two properties that are somewhat difficult to reconcile in practice. On the one hand, a spread requires a relative firm consistency, and a convenient way to do this is by creating a network in the product. On the other hand, a more or less plastic rheology is desirable so that the product does not become much thinner during spreading [2]. Today, biopolymers such as protein (from egg, milk, gelatin), intact and modified starch, and/or polysaccharides (e.g. carrageenan, alginate, pectin) are used to provide structure to the aqueous phase of these food systems. Since no biopolymer on its own can provide the required structure 
alongside a 'plastic' flow, mixtures have been used to achieve the desired combination of properties [6].

Another major nutritional issue in addition to the high fat intake, both in developing and developed countries is that an appreciable fraction of the population, particularly young children, adolescents, the elderly, and women of child-bearing age can suffer from nutrient deficiencies at borderline or pathological levels [7]. Several strategies have been adopted at times in an attempt to address this micronutrient malnutrition $[8,9]$. Micronutrient fortification is now a highly relevant tool worldwide for overcoming micronutrient deficiency [10], and continues to be one the main strategies employed in tackling those global issues [9, 11]. Indeed mandatory fortification programmes are used throughout the world using various food vehicles in delivering a series of nutrients [8], in an attempt to meet the recommended intakes $[12,13]$. Usually the cheapest approach is staple food fortification, however, fortification of spreads has recently been proposed and attempted [14].

In this research an attempt was made to utilise the properties of $\kappa$-carrageenan, a polysaccharide, in terms of mineral binding in addition to its 'structuring' contribution and explore the potential of producing reduced-fat spreads that have been fortified with zinc, copper and iron, whose intakes are traditional and emerging causes for concern $[7,9,10,14]$. Carrageenans are high-molecular weight linear sulphated polysaccharides extracted from many species of red seaweed [15], comprising three major fractions ( $\kappa$-kappa, $\imath$-iota and $\lambda$-lambda). $\kappa$-carrageenan exists as random coils at high temperatures, a coil-to-helix transition occurs on cooling below a certain temperature, which is dependant on the ionic environment [15]. Cations contribute to the formation of electrostatic bonds between the negatively charged double-helices, thereby causing aggregation. The coil-to-helix transition temperature is directly 
related to cation concentration [16]. It has been suggested that the presence of divalent cations such as $\mathrm{Ca}^{2+}$ may link the negatively charged polyions and that these $\mathrm{Ca}^{2+}$ bridges reinforce the gel network structure [17]. Although research has been carried out on the effects of various cations [18], little is known about the effects of divalent cations from different metals such as zinc or copper or for that matter the effects of trivalent cations from metals such as iron. Fortifying low-fat spreads with those cations is expected to have an effect on both the oxidative and textural stability of the spreads, therefore the peroxide values of the produced spreads were monitored over the course of storage and their textural stability was evaluated using the penetrometer, a tool first used for the evaluation of spreads and butters in 1959 [19] but still very widely used today [4, 20-23]. This is a simple, compression-type test which can give an unequivocal characterisation of the mechanical properties of the product [24].

\section{Materials and methods}

\section{Production of reduced-fat spreads}

A ten $\mathrm{kg}$ reduced-fat spread (60\% fat) with a commercial-type formulation was manufactured with the following formulation: an oil phase containing $5860 \mathrm{~g}$ vegetable oil blend (code BDG:WPGLTC, Cargill, France) and $60 \mathrm{~g}$ monoglyceride emulsifier (Paalsgaard 0291, Grinstead A/S, Braband, Denmark); and an aqueous phase containing $3816 \mathrm{~g}$ distilled and deionised water, $170 \mathrm{~g}$ salt (Salt Union, Cheshire, England), 50 g sodium caseinate (Dairygold Foods, Mitchelstown, Co Cork, Ireland), $25 \mathrm{~g}$ sodium alginate (Grinstead Alginate FD 155, Danisco, Denmark), $10 \mathrm{~g}$ buttermilk powder (Tipperary Co-op, Tipperary, Ireland) and $2.5 \mathrm{~g}$ citric acid (Univar Ireland Ltd., Dublin, Ireland). 
Using the same manufacturing process, a reduced-fat spread was prepared by replacing the aqueous phase with $5975 \mathrm{~g}$ water and $25 \mathrm{~g}$ א-carrageenan (Deltagel P379; Kerry Biosciences, Carragiline, Co. Cork, Ireland). The א-carrageenan contained $5.8 \%$ potassium, $0.4 \%$ sodium, $0.4 \%$ calcium and $0.4 \%$ magnessium. A series of fortified reduced-fat spreads were also prepared by including iron, zinc or copper at levels of $0.08-20 \mathrm{mM}$ (ion concentration in final product). The iron (iron (III) chloride), zinc (zinc chloride) and copper (copper (II) chloride dihydrate) were reagent grade or better and obtained from BDH Chemicals (Poole, England). The levels of addition were such as to cover $0-100 \%$ of the recommended RDA $[11,12]$. The pilot scale processing was carried out in a Perfector scraped surface heat exchanger (Gerstenberg and Agger, Copenhagen, Denmark) with a 25-litre jacketed tank connected to a 3-piston pump which fed the Perfector unit. The initial mixing of the oil and aqueous phases was carried out in a Silverson mixer (model AX3, Silverson Machines Ltd., Waterside, Chesham, Bucks, England). The production process is presented schematically in Figure 1.

\section{Peroxide value}

Peroxide values were measured to determine oxidation according to the official AOAC method [25]. All determinations were carried out in duplicate, after storage at $5^{\circ} \mathrm{C}$ for 1,8 and 15 days, unless values were in the region of $5 \mathrm{mEq} \mathrm{O} / \mathrm{kg}$ in which cases the samples were considered spoilt and were discarded.

\section{Measurement of the hardness of Spreads with Cone Penetrometer}

A Seta 1719 Universal Penetrometer and Controller MK.VI supplied by StanhopeSeta Ltd. Station Road, Chertsey, Surrey, KT16 8BG, England, was used for measurement of hardness. 


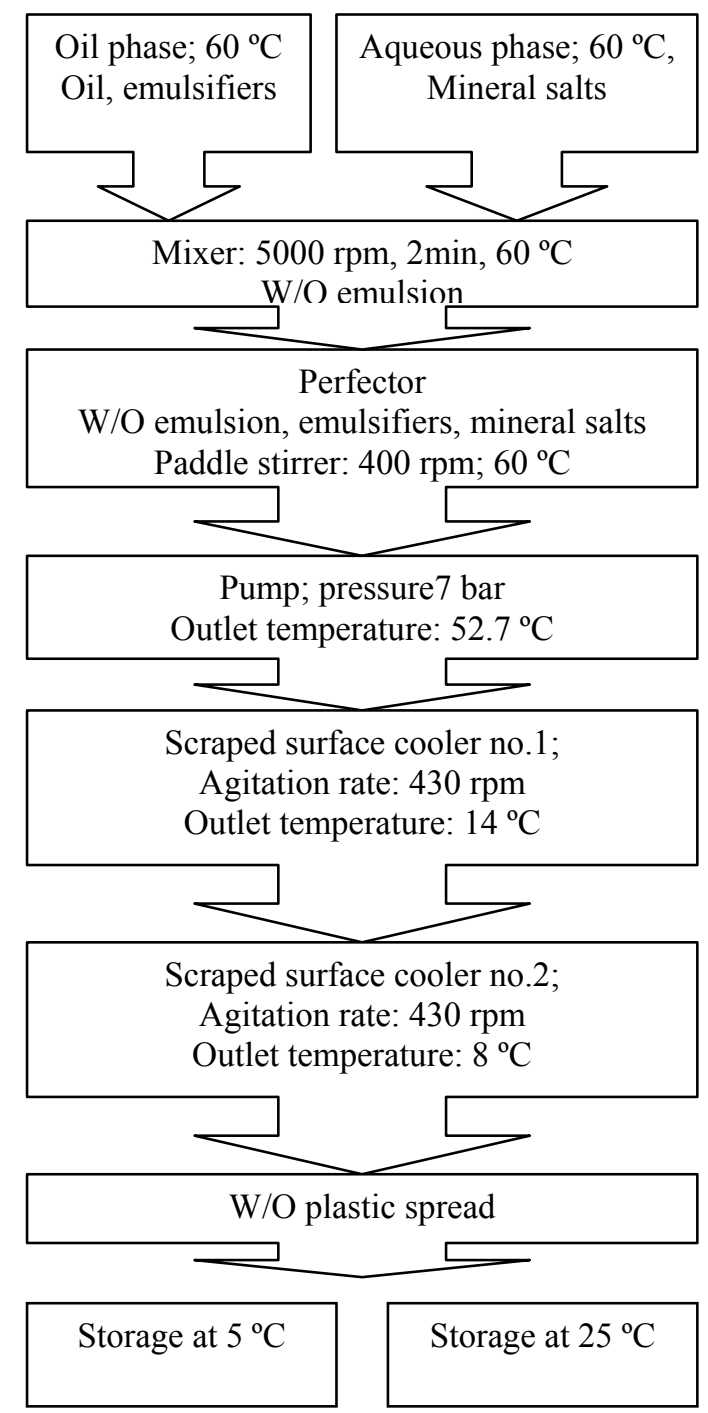

Figure 1 Schematic representation of the production of reduced-fat spreads.

A $20^{\circ}$ stainless steel cone was used, which weighed $76.54 \mathrm{~g}$. Release time was $5 \mathrm{~s}$. Samples were held at testing temperature for at least 24 hours before testing. Penetration readings (in tenths of a millimetre) were obtained and yield values were calculated using equation 1 .

$$
C=K W / P^{1.6}
$$

Where $\mathrm{C}$ is the Yield value in $\mathrm{g} / \mathrm{cm}^{2}, \mathrm{~W}$ is the weight of cone and shaft assembly in grams, $\mathrm{K}$ is a factor dependant on the angle of the cone (for a 20 degree cone $\mathrm{K}=$ 
19000), and $\mathrm{P}$ is the penetration depth (in 5 seconds). All measurements were performed in triplicate.

\section{Statistical Analysis}

Analysis of variance (ANOVA) was carried out using SigmaStat (version 3.0; Jandel Scientific, Corte Madera, CA, USA). Student-Newman-Keuls pairwise-comparison test was used to determine differences between treatment means. Treatment means were considered significantly different at $\mathrm{P} \leq 0.05$.

\section{Results and discussion}

\section{Oxidative stability}

The peroxide values of samples stored at $5^{\circ} \mathrm{C}$ were measured and the results are summarised in Table 1. For the industry the samples are considered rancid and unacceptable when peroxide values (PV) are over 5, while ideally PV should be below 1-1.5. In this trial therefore we stopped measuring and discarded the samples once the PV was in the region of 5. In addition to the fortified reduced-fat spreads, a control containing $\kappa$-carageenan but no mineral salts and a control based on a commercial recipe were also tested. As can be seen from Table 1, the commercial recipe spread was the most resistant to oxidation. Amongst the rest of the sample, the $\kappa$-carageenan control exhibited the greatest stability against oxidation, following the trend suggested previously by Keogh [26] for spreads stored at $4^{\circ} \mathrm{C}$. The addition of Fe in any level caused unacceptable rancidity levels in the spreads even after one day of storage, while after 7 days all samples were completely spoilt. Spreads containing lower concentrations of $\mathrm{Cu}(0.08-4 \mathrm{mM})$ gave acceptable $\mathrm{PV}$ after one day of storage, however after 8 days all samples containing $>4 \mathrm{mM}$ were rancid, while the lower 
Table 1 Peroxide values of reduced-fat spreads

\begin{tabular}{ccccc}
\hline & $\begin{array}{c}\text { Mineral } \\
\text { Concentration } \\
\text { Sample }\end{array}$ & \multicolumn{3}{c}{ Peroxide Value (mEq O/kg) } \\
\cline { 3 - 5 } (mM) & Day 1 & Day 8 & Day 15 \\
\hline $\begin{array}{c}\text { Commercial } \\
\text { recipe control }\end{array}$ & 0 & 0.42 & 0.42 & 0.59 \\
Carragenan & & & & \\
control & & 0.34 & 0.51 & 1.10 \\
$\mathrm{Zn}$ & 0.3 & & & \\
$\mathrm{Zn}$ & 1.5 & 0.34 & 0.76 & 1.15 \\
$\mathrm{Zn}$ & 3 & 0.34 & 0.98 & 1.35 \\
$\mathrm{Zn}$ & 7.5 & 1.02 & 1.78 & 1.86 \\
$\mathrm{Zn}$ & 15 & 1.02 & 1.95 & 1.95 \\
$\mathrm{Cu}$ & 0.08 & 1.25 & 2.03 & 2.12 \\
$\mathrm{Cu}$ & 0.4 & 1.48 & 2.71 & 3.05 \\
$\mathrm{Cu}$ & 0.8 & 1.6 & 2.88 & 3.05 \\
$\mathrm{Cu}$ & 4 & 1.78 & 2.88 & 3.05 \\
$\mathrm{Cu}$ & 10 & 2.28 & 5.25 & N/A \\
$\mathrm{Cu}$ & 20 & 2.69 & 5.25 & N/A \\
$\mathrm{Fe}$ & 0.3 & 1.95 & 5.25 & N/A \\
$\mathrm{Fe}$ & 1.5 & 2.42 & 4.65 & N/A \\
$\mathrm{Fe}$ & 3 & 2.62 & 5.25 & N/A \\
$\mathrm{Fe}$ & 7.5 & 2.68 & 5.25 & N/A \\
$\mathrm{Fe}$ & 15 & 2.71 & 5.25 & N/A \\
& & & 5.25 & N/A \\
\hline
\end{tabular}

concentration also had peroxide values that would not be acceptable in an industrial setting. The effect of added $\mathrm{Zn}$ in the peroxide values of the reduced-fat spreads was much lower. Indeed the samples containing $0.3 \mathrm{mM}$ were comparable with the $\kappa$ carageenan control throughout the storage period, but still had higher values than the commercial control. Briend [14] has suggested that limited contact with oxygen and humidity, and absence of water are all very favourable factors for obtaining a prolonged shelf life for a fortified spread by increasing its resistance to oxidation. In our case however it would appear that the added ions negated these factors, with the trivalent Fe exhibiting, as anticipated, the most susceptible profile. Transition metals such as copper and iron are in particular expected to catalyse, and thus accelerate, the breakdown of oxidation products $[27,28]$. This breakdown is leading to a series of secondary oxidation products which are associated with the deterioration of the 
organoleptic properties, and in particular aldehydes, due to their very low flavour threshold [28].
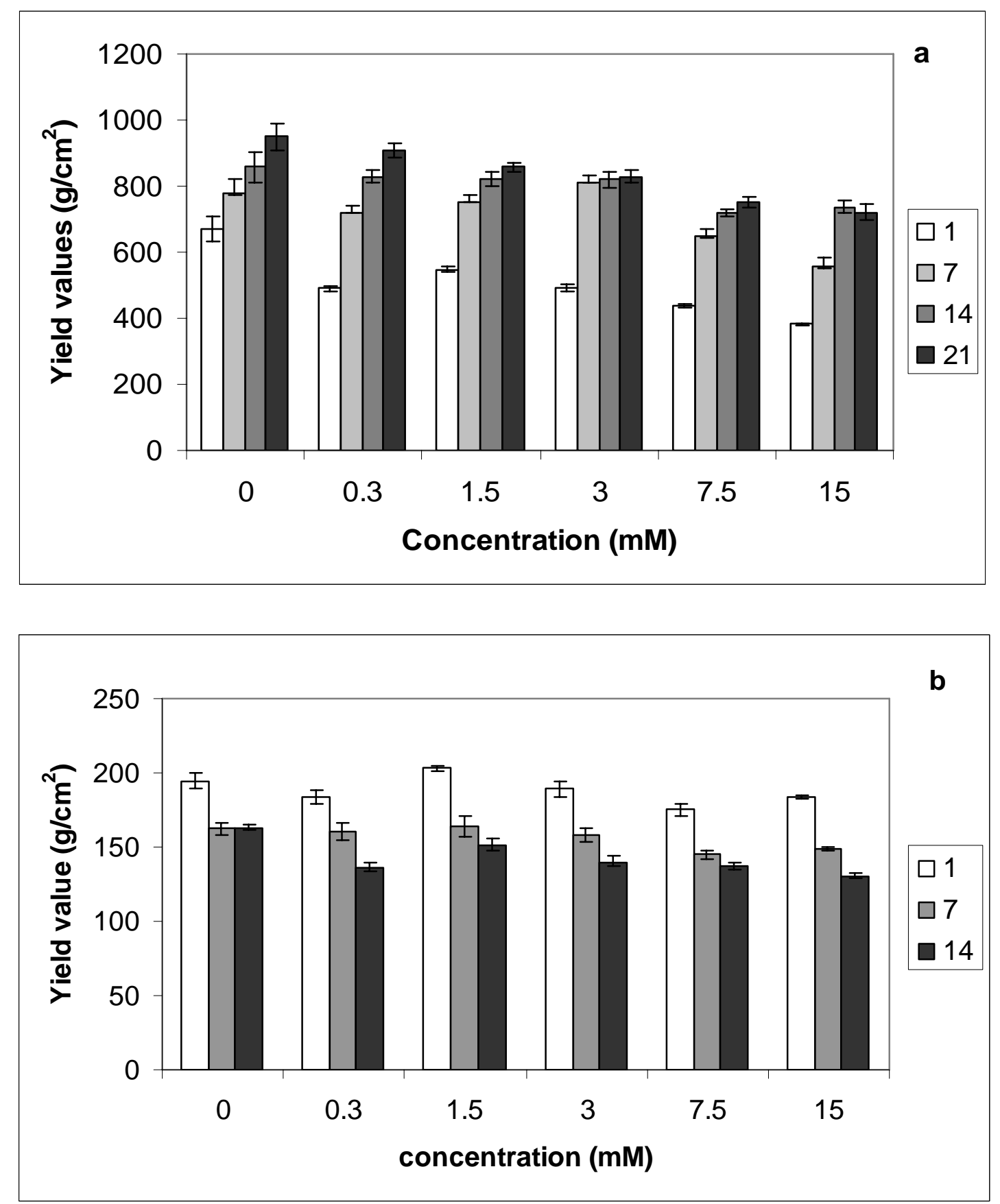

Figure 2 Effect of Zn fortification on the textural stability of reduced-fat spreads stored at 5 (a) and $25^{\circ} \mathrm{C} \mathrm{(b)} \mathrm{for} \mathrm{1,7,} 14$ and 21 days. Average of three measurements, error bars represent standard deviation. 
Overall the results suggest that mineral fortified reduced-fat spreads were inferior to the controls, with only those containing lower concentrations of $\mathrm{Zn}$ having acceptable PV after 15 days storage. The carrageenan-metal complexes are known to form gels [15-17], and this was confirmed by the reduced-fat spread production, however, it is believed that in our case the binding was not complete thus allowing free metal ions in the spreads which in turn promoted rancidity through autoxidation.

Of course some well established methods exist for the prevention of oxidation [29] and a future approach could include the addition to the spreads of a variety of antioxidants [28, 29].

\section{Spread hardness}

The texture of spreads is mostly determined by the properties of the fat phase [2]. In the production of spreads, crystallisation of fat occurs on cooling at lower temperatures. The agglomerated fat crystals dispersed in liquid oil play a critical role in determining the texture/consistency of the system $[2,30]$.

The textural stability of the spreads was monitored using the penetrometer. The results for the samples stored at $5^{\circ} \mathrm{C}$ are presented in Figures 2a, 3a and 4a. The significances of the differences are presented in Table 2. For the Zn-containing samples stored at $5^{\circ} \mathrm{C}$ (Fig. 2a) a clear trend was observed whereby the yield values increased between 1 and 14 days storage. No further increase was observed upon storage for a third week (days 14-21), however, over the 21 days of storage the control samples (no $\mathrm{Zn}$ added) continued to strengthen. Maximum strength was observed for spreads containing 1.5 $\mathrm{mM} \mathrm{Zn}$. For samples measured after 1 and 7 days the addition of any amount of $\mathrm{Zn}$ had a weakening effect when compared with the control, and this was also true for samples stored for 21 days. It would therefore appear that addition of $\mathrm{Zn}$ had a 
weakening effect on the spreads and, furthermore, no additional hardening was noted after the second week of storage (Tab.2).

Table 2 Statistical significance of mean yield values differences for reduced fat spreads fortified with various amounts of minerals and stored at 5 and $25^{\circ} \mathrm{C}$. Different letters indicate significant difference $(\mathrm{p}>0.05)$. Letters $a-f$ refer to differences between concentrations within a certain storage time (comparison across rows), and letters $w-Z$ refer to differences over storage within a concentration (comparison within columns).

Sample Storage

\begin{tabular}{llllllll}
\hline & (days) & 0 & 0.3 & 1.5 & 3 & 7.5 & 15 \\
\hline Zn 5 & 1 & $a z$ & $b z$ & $b z$ & $b z$ & $b z$ & $b z$ \\
& 7 & $a y$ & $b y$ & $a y$ & $b y$ & $b y$ & $a y$ \\
& 14 & $b x y$ & $b c w$ & $a x$ & $a x$ & $b x$ & $c x$ \\
& 21 & $a x$ & $d x$ & $b x$ & $b c x$ & $c d x$ & $b c x$ \\
\hline Zn 25 & 1 & $b y$ & $c d x$ & $a x$ & $b c x$ & $d x$ & $c d x$ \\
& 7 & $a x$ & $a y$ & $a y$ & $a y$ & $b y$ & $b y$ \\
& 14 & $a x$ & $c d z$ & $b z$ & $c z$ & $c d z$ & $d z$ \\
\hline
\end{tabular}

\begin{tabular}{llllllllll}
\hline Sample & \multirow{2}{*}{$\begin{array}{l}\text { Storage } \\
\text { (days) }\end{array}$} & 0 & 0.008 & 0.08 & 0.4 & 0.8 & 4 & 10 & 20 \\
\hline Cu 5 & 1 & $a z$ & $c d z$ & $a z$ & $b z$ & $a z$ & $e z$ & $d y$ & $c z$ \\
& 7 & $a y$ & $d y$ & $a y$ & $a y$ & $b y$ & $c y$ & $b x$ & $b y$ \\
& 14 & $a x y$ & $c x$ & $a x$ & $a x$ & $a x$ & $c x$ & $c x$ & $b x$ \\
& 21 & $a x$ & $c w$ & $b x$ & $a w$ & $b x$ & $c w$ & $c x$ & $c x$ \\
\hline Cu 25 & 1 & $b y$ & $b x$ & $b x$ & $b x$ & $a x$ & $c x$ & $d x$ & $e x$ \\
& 7 & $b c x$ & $a x$ & $d x$ & $b y$ & $b c y$ & $d y$ & $e y$ & $f y$ \\
& 14 & $a x$ & $c y$ & $b y$ & $b z$ & $b z$ & $d z$ & $d e z$ & $e z$ \\
\hline Sample & Storage & & & \multicolumn{7}{c}{ Concentration $(\mathrm{mM})$} & & \\
\hline & $($ days) & 0 & 0.3 & 1.5 & 3 & 7.5 & 15 \\
\hline Fe 5 & 1 & $a z$ & $b c z$ & $b z$ & $b c y$ & $c y$ & $d z$ \\
& 7 & $a b y$ & $b y$ & $b y$ & $a x$ & $b x$ & $c y$ \\
& 14 & $a x y$ & $a x$ & $a x$ & $a x$ & $b x$ & $b x$ \\
& 21 & $a x$ & $a x$ & $b w$ & $b x$ & $c x$ & $c x$ \\
\hline Fe 25 & 1 & $a y$ & $d z$ & $c x$ & $b x$ & $e z$ & $f z$ \\
& 7 & $a x$ & $b x$ & $d y$ & $a y$ & $a x$ & $c y$ \\
& 14 & $a x$ & $d y$ & $d z$ & $e z$ & $c y$ & $b x$ \\
\hline
\end{tabular}



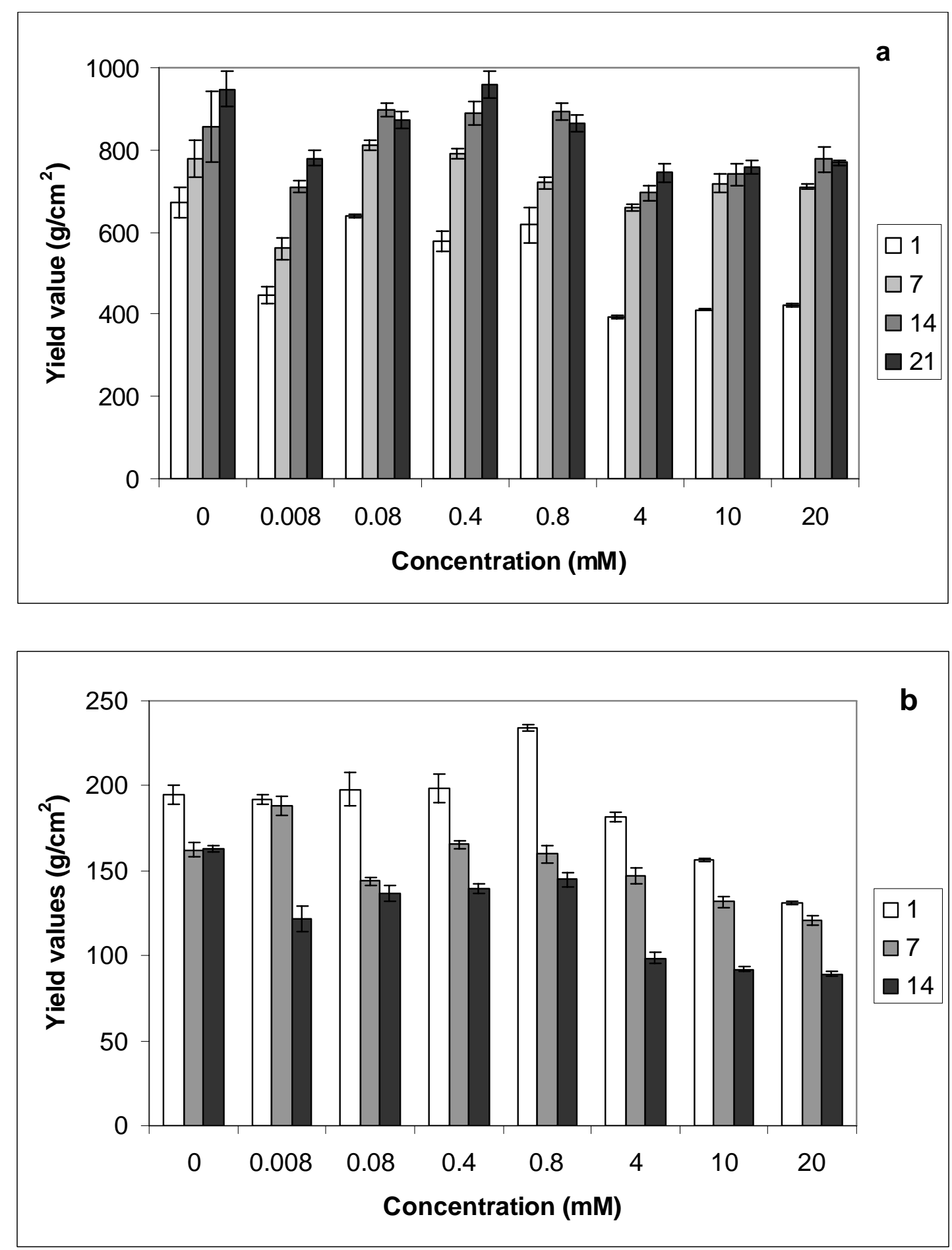

Figure 3 Effect of $\mathrm{Cu}$ fortification on the textural stability of reduced-fat spreads stored at 5 (a) and $25^{\circ} \mathrm{C}$ (b) for 1,7, 14 and 21 days. Average of three measurements, error bars represent standard deviation. 

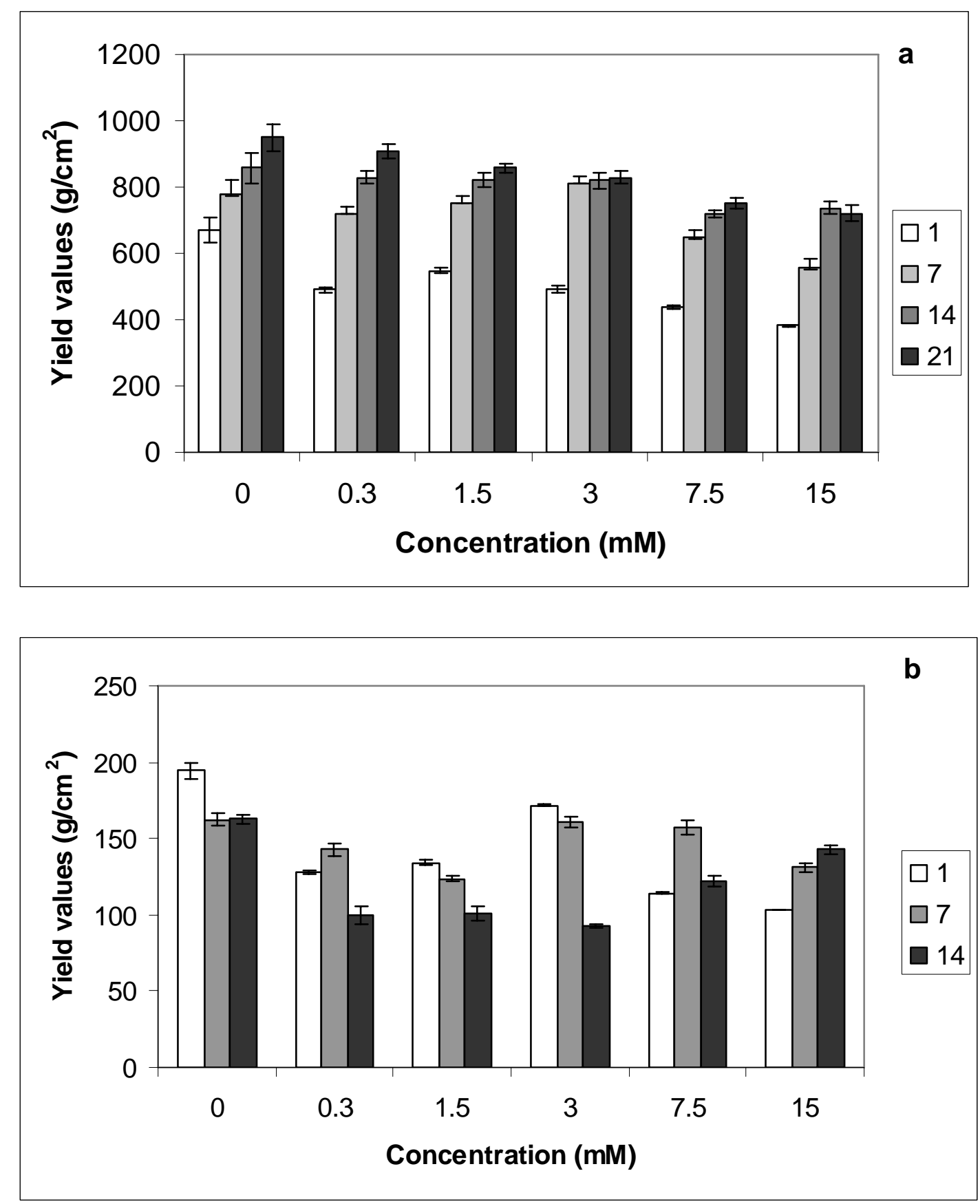

Figure 4 Effect of Fe fortification on the textural stability of reduced-fat spreads stored at 5 (a) and $25^{\circ} \mathrm{C}$ (b) for 1,7,14 and 21 days. Average of three measurements, error bars represent standard deviation. 
The samples fortified with $\mathrm{Cu}$ and stored at $5^{\circ} \mathrm{C}$ (Fig. 3a) all exhibited a weaker behaviour than the control after 1 day of storage (Tab. 2). Samples throughout the $\mathrm{Cu}$ concentration range got stronger with storage up to 14 days, but upon storage for a third week (days 14-21) there was no clear pattern as some samples kept strengthening while others did not. The stronger samples were those containing $0.4 \mathrm{mM} \mathrm{Cu}$, which were comparable with the non-mineral containing control throughout the storage period (Tab. 2).

The spreads containing the highest concentrations of $\mathrm{Cu}(4,10$ and $20 \mathrm{mM})$ weakened noticeably compared with the control after one day storage but seemed to recover most of the yield values upon further storage, without however reaching the levels of the control.

Fe-fortified spreads when stored at $5^{\circ} \mathrm{C}$ (Fig.4a) exhibited a different behaviour when compared with the $\mathrm{Zn}$ - and $\mathrm{Cu}$ - fortified samples. These samples strengthened throughout the storage period of 21 days, the only exception being the sample with the highest Fe concentration $(15 \mathrm{mM})$. The highest yield values were observed for samples containing $0.3 \mathrm{mM} \mathrm{Fe}$, while increasing Fe concentration lead to progressively lower values over the storage period. When compared to the control, Fe-containing samples were consistently weaker, throughout the trials (Tab. 2).

In contrast, samples stored at $25^{\circ} \mathrm{C}$ (Fig. 2b, 3b, 4b) showed a different behaviour. Their highest yield values were observed after 1 day's storage and all Zncontaining spreads (Fig. 2b) consistently became weaker upon prolonged storage. The control samples differed slightly in that they appeared to be unaffected and did not deteriorate further after the first week of storage, i.e. there was no notable difference in the yield values for samples stored for 7 and 14 days (Tab. 2). As for the samples stored at $5^{\circ} \mathrm{C}$, the highest yield values, corresponding to the stronger samples, were 
observed for the spreads containing 1.5 mM Zn. Notably, for the samples stored at $25^{\circ} \mathrm{C}$, spreads containing $\mathrm{Zn}$ were not weaker than the control for the first week, but did appear to be weaker after 14 days of storage (Tab. 2). With storage, the fat crystals are probably the main emulsion stabilising factor in the spreads, so storage at higher temperatures results in elimination of this emulsion stabilising effect of the fat crystals [31]. This is a result of the commercial necessity whereby a spread would be required to lose some of its consistency in the mouth, which is caused by melting of the fat phase as well as dispersal of the spread [2]. This behaviour becomes more prominent at higher temperatures, which more closely resemble the temperature of the mouth.

The $\mathrm{Cu}$-containing samples stored at $25^{\circ} \mathrm{C}$ (Fig. $3 \mathrm{~b}$ ), as for the case of $\mathrm{Zn}$, weakened throughout the storage period, but noticeably the $0.8 \mathrm{mM} \mathrm{Cu}$-containing sample was stronger than the control after 1 day storage. Interestingly the sample containing the lowest amount of $\mathrm{Cu}(0.008 \mathrm{mM})$ had the highest yield values after 7-day storage.

For spreads containing iron stored at $25^{\circ} \mathrm{C}$ (Fig.4b), no obvious pattern was observed. Some of the samples progressively weakened, while others strengthened over time. The highest yield values after one and seven days storage were exhibited by the spread containing $3 \mathrm{mM} \mathrm{Fe}$, while after 14 days the sample with the maximum content of Fe $(15 \mathrm{mM})$ was the strongest. All samples however were consistently weaker (lower yield values) than the control (Tab. 2).

\section{Conclusions}

The results confirm that it is possible to use of $\kappa$-carageenan for the binding of mineral salts. The reduced-fat spreads produced, however, appear to be more susceptible to oxidation, particularly those containing $\mathrm{Cu}$ and Fe. Samples containing 0.3 and $1.5 \mathrm{mM} \mathrm{Zn}$ (corresponding to 2 and $10 \%$ of the recommended RDA, based on 
a $25 \mathrm{~g}$ serving) were affected much less by oxidation, while also exhibiting comparable textural stability compared with the non-mineral containing spread. It would appear, therefore, that reduced-fat spreads fortified with $\mathrm{Zn}$ can be readily produced with acceptable oxidative stability without any major detrimental effects texturally. The combined effect of mineral fortification and antioxidant addition needs to be established through further work.

\section{Acknowledgements}

The authors would like to acknowledge the help of J.Roche in the preparation of the spreads, and J.O'Reilly for useful comments and advice.

\section{References}

1. Chronakis, I.S.;Kasapis, S. A Rheological Study on the Application of Carbohydrate-Protein Incompatibility to the Development of Low Fat Commercial Spreads. Carbohydr.Polym., 1995, 28(4), 367-373.

2. Bot, A.;Vervoort, S., Hydrocolloid Functionality in Spreads and Related Products, in Gums and Stabilisers for the Food Industry 13, P.A. Williams and G.O. Phillips, Editors. Royal Society of Chemistry: Cambridge. 2006; 381394.

3. Keogh, M.K., Ph.D. Thesis: The Stability to Inversion of a Concentrated Water-in-Oil Emulsion. 1993, University College Cork.

4. Patel, A.A.;Gupta, S.K. Studies on a Soy-Based Low-Fat Spread. J. Food Sci., 1988, 53(2), 455-459.

5. Keogh, M., K., Chemistry and Technology of Milk Fat Spreads, in Advanced Dairy Chemistry Volume 2 Lipids, P.F. Fox, Editor. Chapman \& Hall: London. 1995; 213-246.

6. Evangeliou, V.;Alevisopoulos, S.;Kasapis, S. Application of Stress-Controlled Analysis to the Development of Low Fat Spreads. Journal of Texture Studies, 1997, 28, 319-335.

7. Richardson, D.P. Food Fortification. Proc.Nutr.Soc., 1990, 49, 39-50.

8. Darnton-Hill, I.;Nalubola, R. Fortification Strategies to Meet Micronutrient Needs: Successes and Failures. Proc.Nutr.Soc., 2002, 61, 231-241.

9. $\quad$ Fletcher, R.J.;Bell, I.P.;Lambert, J.P. Public Health Aspects of Food Fortification: A Question of Balance. Proc.Nutr.Soc., 2004, 63, 605-614.

10. Rosado, J.L. Zinc and Copper: Proposed Fortification Levels and Recommended Zinc Compounds. J.Nutr., 2003, 133(9), 2985S-2989S.

11. FAO, Food Fortification: Technology and Quality Control. Fao Food and Nutrition. Vol. 60. Rome: 1996. 
12. FAO/WHO, Vitamin and Mineral Requirements in Human Nutrition: Report of a Joint Fao/Who Expert Consultation. Second ed. Bangkok: 1998.

13. Scientific Committee on Food (Scf) Tolerable Upper Intake Levels for Vitamins and Minerals 2003 [cited 22 May 2007]; Available from: http://europa.eu.int/comm/food/fs/sc/scf/out80 en.html.

14. Briend, A. Highly Nutrient Dense Spreads: A New Approach to Delivering Multiple Micronutrients to High Risk Groups. Br.J.Nutr., 2001, 85(supplement 2), S175-S179.

15. Viebke, C.;Borgstrom, J.;Piculell, L. Characterisation of Kappa- and IotaCarrageenan Coils and Helices by Malls/Gpc. Carbohydr.Polym., 1995, 27(2), 145-154.

16. Rochas, C.;Rinaudo, M. Activity Coefficients of Counterions and Conformation in Kappa-Carrageenan Systems Biopolymers, 1980, 19(9), 1675-1687.

17. Vega, C.;Dalgleish, D.G.;Goff, H.D. Effect of [Kappa]-Carrageenan Addition to Dairy Emulsions Containing Sodium Caseinate and Locust Bean Gum. Food Hydrocolloids, 2005, 19(2), 187-195.

18. Hermansson, A.M.;Eriksson, E.;Jordansson, E. Effects of Potassium, Sodium and Calcium on the Microstructure and Rheological Behaviour of KappaCarrageenan Gels. 1991, 16, 297-320.

19. Haighton, A.J. The Measurement of the Hardness of Margarine and Fats with Cone Penetrometers. J. Am. Oil Chem. Soc., 1959, 36, 345.

20. Wright, A.J.;Scanlon, M.G.;Hartel, R.W.;Marangoni, A.G. Rheological Properties of Milkfat and Butter. J. Food Sci., 2001, 66(8), 1056-1071.

21. Staniewski, B.;Szpendowski, J.;Panfil-Kuncewicz, H.;Malkus, J.;Bohdziewicz, K. The Application of an Ap4/2 Conical Penetrometer for the Evaluation of Spreadability of Selected Table Fats. Milchwissenschaft, 2006, 61(3), 292-296.

22. Kim, B.H.;Shewfelt, R.L.;Lee, H.;Akoh, C.C. Sensory Evaluation of Butterfat-Vegetable Oil Blend Spread Prepared with Structured Lipid Containing Canola Oil and Caprylic Acid. J. Food Sci., 2005, 70(7), s406s412.

23. Strohmaier, W.;Klostermeyer, H.;Deuritz, P.;Windhab, E. Comparison of Different Methods to Determine the Spreadability and Firmness of Processed Cheese. Z.Lebensm.-Unter.Forsch., 1992, 194, 531-535.

24. Van Vliet, T., Rheological Classification of Foods and Instrumental Techniques for Their Study, in Food Texture: Measurement and Perception, A.J. Rosenthal, Editor. Aspen publishers, Inc.: Gaithersburg, MD. 1999; 6596.

25. AOAC, Method 965.33, in Official Methods of Analysis: Association of Analytical Chemists. 1997, Association of Official Analytical Chemists: Gaithersburg, MD. p. 9.

26. Keogh, M., K.;Quigley, T.;Connolly, J.F.;Phelan, J.A. Anhydrous Milk Fat: 4.Low-Fat Spreads. Irish Journal of Food Science and Technology, 1988, 12, $53-75$.

27. Lundberg, W.O., Mechanisms of Lipid Oxidation, in Lipids and Their Oxidation, H.W. Shcultz, Editor. AVI publishing company: Westport, $\mathrm{Cu}$. 1962; 31-51.

28. Chow, C.K.;Gupta, M.K., Treatment, Oxidation and Health Aspects of Fats and Oils, in Technological Advances in Improved and Alternative Sources of 
Lipids, B.S. Kamel and Y. Kakuda, Editors. Blackie Academic and Professional: Glasgow. 1994; 329-359.

29. Gutcho, M., Improving Stability of Fats and Oils, in Edible Oils and Fats Recent Developments. Noyes Data Corporation: Park Ridge, NJ. 1979; 53-76.

30. Precht, D., Fat Crystal Structure in Cream and Butter, in Crystalisation and Polymorphism of Fats and Fatty Acids, N. Garti and K. Sato, Editors. Marcel Dekker: New York. 1988; 305-361.

31. Moran, D.J.P. The Development of Yellow Spreads. Dairy Industries International, 1990, (5), 41-43. 